\title{
Hope as Unique Agent of Resilience in Socio-economically Disadvantaged Adolescents
}

\author{
Zeynep Aydın Sünbül, Ferah Çekici \\ Department of Educational Sciences, Istanbul Medipol University, Istanbul, Turkey
}

\begin{tabular}{l}
\hline \hline Article Info \\
\hline Article history: \\
Received Jul 26, 2018 \\
Revised Sep 20, 2018 \\
Accepted Oct 3, 2018 \\
\hline Keyword: \\
Adolescents \\
Hope \\
Resilience \\
Socio-economically \\
disadvantaged status \\
\hline
\end{tabular}

\begin{abstract}
The aim of this study was to explore the predictive effect of hope for resilience in socio-economically disadvantaged adolescents. Participants of the study were 692 (395 female, 297 male) students attending to 9th, 10th and 11th grades. The age range of the sample was 14-19 $(\mathrm{M}=16.24$, $\mathrm{SD}=.89$ ). A convenient sampling was used to select the participants who are picked from four high schools located in low income regions. In order to collect data, The 14-Item Resilience Scale and Dispositional Hope Scale were used as data collection instruments. The predictive effect of hope on resilience was analyzed through linear regression. Regression analysis yielded that hope explains $48 \%$ of the variance in the resilience scores of participants. This result indicates that hope is a powerful significant predictor of resilience for socio-economically disadvantaged adolescents.
\end{abstract}

Copyright (C) 2018 Institute of Advanced Engineering and Science. All rights reserved.

\section{Corresponding Author:}

Department of Educational Sciences, Istanbul Medipol University, İstanbul Medipol Üniversitesi Kavacık Güney Yerleşkesi Göztepe Mahallesi Atatürk Caddesi No 40/16 34815 Beykoz, Istanbul, Turkey.

Email: zsunbul@medipol.edu.tr

\section{INTRODUCTION}

Resilience is at large defined as the disposition and capability to take on a new lease of life on the face of tough life experiences and stress factors [1]. To explain in depth, resilience is a process of possessing and attaining specific skills, competencies and inner vision in a situation while people struggle to cope with the burdens of their tough experiences [2]. In general, existence of two mechanisms generate a resilient response: a present or former risk setting and an adaptive response despite the unfavorable consequences and problem bundles of such risky experiences [3]. Based on this view, owning a risk factor is characterized as a situation that would possibly results in unfavorable and undesirable consequences leaving off considerable levels of stress to the course of living. Such major risk factors came forward by the resilience literature are, but not limited to, poor socio-economic living conditions, stressful and traumatic experiences, troublesome early childhood incidences and etc. [4].

Referring to the risky contexts as outlined in the resilience framework by Masten and Garmezy [13] adolescents with socio-economically disadvantageous life conditions can be argued as one of these specific risky target groups for directing resilience studies and models [5-6]. Supported in various studies, such group of adolescents suffer from psychological disorders [7-10], affective and behavioral complexities [18], antisocial actions [11], suicidal tendency [12] compared to their peers with a more superior socio-economic condition. On the other hand, emphasized that not all adolescents with low socio-economic status are prone to cultivate psychological and physical complications [13]. Accordingly this premise signals the existence of particular attributes and processes as they battle against the risk company of such adolescents. In addition, revealing and working on these specific mechanisms and attributes that facilitate adolescent resiliency is accepted as essential steps of promoting healthy development in these groups [5-6].

Journal homepage: http://iaescore.com/journals/index.php/IJERE/ 
The literature highlights several resilience studies particularly focus on young people with poor socio-economic conditions. As such, preliminary resilience studies examining the interactions of riskresilience mechanisms included socio-economically disadvantaged groups as their target population. Furthermore, there are recent studies specifically concentrating to uncover the protector and counterproductive agents in this specific group. In such a study, a tentative framework was disclosed over the risk and protective elements interfering in the resilience process of socio-economically disadvantaged children and adolescents [14]. According to this examination, the pathways to resilience for this group were put forwarded as access to sanitary and educational resources, internalizing the ethos, perceived support from close surrounding, familial attitudes, promoting connections, personal agents of inwardness, self-control, self-confidence and etc. In another study, resilience factors were investigated in young people suffering from poorness, violence and addiction [15]. The results of this study disclosed that personal attributes such as hopefulness, effective regulation of self, favorable self-perception and social factors like positive parenting practices, promoting communal means, religion are the generic protective ingredients of resilience in this group.

Current study is another attempt to also study resilience in socio-economically disadvantaged adolescents through considering the emerged therapeutic effects of an individual factor, hope that has slightly been underlined in resilience studies with socioeconomically disadvantaged adolescents. Hope is defined as "a positive motivational state that is based on an interactively derived sense of successful (a) agency (goaldirected energy) and (b) pathways (planning to meet goals)" [16]. Individuals exhibit goal directed actions and those goals that are valuable and uncertain carry the hope potential as they put direction and meaning to the life [17]. As well, being hopeful affects cognitive, emotional and behavioral condition of individuals toward a future in that good experiences are expected to transcend bad ones. Based on these views, the protective structure and characteristic of hope could also be generalized to adolescents suffering from a range of complex risky pathways, by the potential of this attribute in creating a positive and purposeful expectation toward future and encouraging a copious way of life in spite of the suffering and obstacles of living [18].

Bringing all together, based on the current efforts and understanding of resilience process specifically in at risk adolescents, hope was assumed to be a promising protective layer for these groups. In this direction, this study examines the strength and feasibility of the hopeful pathway and thinking in explaining the resilience tendencies of adolescents with poor socio-economic conditions.

\section{RESEARCH METHOD}

\subsection{Participants}

Participants of this study were composed of $6929^{\text {th }}, 10^{\text {th }}$ and $11^{\text {th }}$ grade students residing in socioeconomically disadvantaged districts. In the sample group there were 395 girls $(57.08 \%)$ and 297 boys $(42.02 \%)$ with the average age of 16.24 . The features of the sample group are presented in Table 1 .

Table 1. The socio-demographic features of the sample

\begin{tabular}{llcc}
\hline Variable & Groups & $\mathrm{N}$ & $\%$ \\
\hline Income & $500 \mathrm{TL}$ and below & 16 & 2.3 \\
& $501-1000 \mathrm{TL}$ & 17 & 2.5 \\
& $1001-1500 \mathrm{TL}$ & 151 & 22.6 \\
& $1501-3000 \mathrm{TL}$ & 305 & 45.7 \\
\multirow{5}{*}{ Mother Education } & 178 & 26.7 \\
& 3001 TL and above & 41 & 5.9 \\
& Illiterate & 321 & 46.4 \\
& Elementary school & 164 & 23.7 \\
& Secondary school & 125 & 18.1 \\
& High school & 38 & 5.5 \\
& College and above & 9 & 1.3 \\
& Illiterate & 234 & 33.8 \\
& Elementary school & 185 & 26.7 \\
& Secondary school & 177 & 25.6 \\
& High school & 76 & 11 \\
\hline
\end{tabular}

Income and level of education are the most essential criteria indicating low-socio economic conditions [19]. As shown in Table 1, almost \%74 of the sample group have the income less than $3001 \mathrm{TL}$. In addition, the low education levels of mothers (only \% 6 of them are university graduate) and fathers of the 
participants (only \%11 of them are university graduate) also tentatively point to the disadvantegous socioeconomic conditions for the sample group.

\subsection{Instruments}

\subsubsection{The 14-Item Resilience Scale (RS-14)}

Resilience Scale (RS) is a 14-item inventory assessing resilience levels in adolescent population. The scale is a 7 point Likert type scale from 1 (Strongly disagree) to 7 (Strongly agree) for each item. Higher scores mean superior levels of resilience tendencies. Cronbach alpha value of the scale was calculated .91 indicating a satisfactory consistency for the entire scale [20]. The Turkish translation and adaptation study of RS-14 supported the single factor structure of the scale $(\chi 2 / \mathrm{df}=4.4, \mathrm{RMSEA}=.07, \mathrm{CFI}=.93$; TLI $=.91)$ along with the Cronbach alpha value of .81 [21]. The Cronbach alpha level of RS-14 was also found .81 in the current study.

\subsubsection{Dispositional Hope Scale (DHS)}

Dispositional Hope Scale [22] assesses a global trait based hope score for individuals above 15 years old. The scale is in 4-point Likert-type scale ranging from Definitely False to Definitely True. There are twelve items in the scale distributed as follows: pathways subscale (4 items), agentic thinking subscale (4 items) and four negative statements called fillers that aren't related to hope. Internal consistency scores for the scale ranged between .74 and .84 in six studies and the scale showed good relations with measures of coping, negative affect and goal-oriented behaviors [22]. In the Turkish adaptation and validity study of DHS, the scale was administered to 103 undergraduates and Cronbach alpha level was reported as .65 for the scale [23]. Then, with a group of 74 students, test-retest reliability was examined and found .66 in four week interval. In this study, the Cronbach alpha level for DHS was also found .81.

\section{RESULTS DISCUSSION}

In order to analyze the data, linear regression analysis was utilized to examine the predictive effect of hope over resilience. After checking the assumptions of linear regression analysis, descriptive statics for the variables (mean, SD and correlation matrix) were examined in the first step and appeared in Table 2.

Table 2. Means, standard deviations and intercorrelations for hope and resilience

\begin{tabular}{lccc}
\hline Variable & $\mathrm{M}$ & $\mathrm{SD}$ & $\mathrm{r}$ \\
\hline Resilience & 75.77 & 13.65 & $.69^{* * *}$ \\
Predictor Variable & & & 4.07 \\
Hope & 25.59 & &
\end{tabular}

Based on the intercorrelations presented in Table 2, it can be concluded that there is a significant, medium correlation between hope and resilience scores. Moreover, hope is seen to be positively correlated to resilience meaning that as hope scores of participants increase, resilience levels of participants also increase and vice versa.

At the next step of the analysis, significance of regression coefficient, squared semi-partial correlation, $\mathrm{R}^{2}$ and adjusted $\mathrm{R}^{2}$ values, unstandardized/standardized weights summary of simple linear regression analysis were checked and results are presented in Table 3.

Table 3 Summary of linear regression analysis for hope predicting resilience $(N=692)$

\begin{tabular}{lccccccc}
\hline Variable & $\mathrm{B}$ & $\mathrm{SE}$ & $\mathrm{B}$ & $\mathrm{T}$ & $\mathrm{P}$ & $\Delta \mathrm{R}^{2}$ & $\mathrm{R}^{2}$ \\
\hline (Constant) & 16.42 & 2.36 & & 6.93 & .000 & .48 & .48 \\
Hope & 2.31 & .91 & .69 & 25.39 & & & \\
\hline Notes. $\mathrm{F}(1,690)=644.45,(\mathrm{p}=.000)$.
\end{tabular}

Table 3 shows that hope significantly predicts resilience $(\mathrm{F}(1.690)=644.5, \mathrm{p}<.001)$. The adjusted $\mathrm{R}^{2}$ value of .48 indicates that hope explains $48 \%$ of the variance, nearly half of the variance, for the resilience scores of participants. Based on the beta coefficient value emerged, it can be stated that hope has a highly significant contribution for explaining the variance in resilience $(\beta=.69, \mathrm{t}=25.39, \mathrm{p}<.001)$.

Hope as a Unique Agent of Resilience in Socio-economically Disadvantaged ... (Zeynep Aydın Sünbül) 
The study proposed hope as a protective factor over resilience in underprivileged adolescents. The results of the study supported the hypothesized relationship that hope is a significant positive predictor of resilience in these adolescents. Despite the distinct social inequalities that individuals face, society is also a source of social opportunities and hope through offering attainment to certain resources that facilitate social mobility. This hope is characterized as the individuals' experience of certain possibilities that their life presents, otherwise they feel entrapment as the sense of no direction to arrive [24]. In this view, it is clearly underlined that as well as the challenging injustices of societal contexts, individuals who hold hope through noticing the social resources and possibilities in their life may find more meaningful and purposeful directions. Otherwise, they become stuck in the compelling personal, familial and social enforcements that they perceive in their social condition. In this sense, hope can be accepted as a mechanism that evoke the belief and faith that adversities can be overcome through specifically focusing on and adapting the resources and gainings that life brings in spite of the social or economic challenges [24].

There are a number of studies indicating certain hope related mechanisms predicting resilience in socio-economically disadvantaged adolescents. In such a study, the role and correlates of hope among resilient adolescents were examined [25]. The results of that study showed that hope is a way to reach to the academic and long-term goals, forming goals by the modeling family roles and also a desire for a high quality life, accessing various support systems and utilizing personal coping strategies in the face of a number of adversities they experience (e.g. discrimination). At another study, the experience of hope and hopelessness in low-income African-American adolescents was investigated [26]. The study revealed that the experience of hope in these adolescents is linked to five attitudes as caring connections, spirituality, education, "basic needs," and "gonna make it mentality." As well, hopelessness was found to be linked to negative attitudes and beliefs, external constraints, negative behaviors, and deleterious environmental conditions. The results of this study highlighted both hope and hopelessness are distinct attributes beyond the cognitive meanings of goal attainment for low-income African American adolescents. Based on these studies, it can also be summarized that both the perception as well as the correlates of hopefulness facilitate wellbeing and empower strength to overcome the challenging pathways of the life. To put it another way, as well as hope, other individual level protective factors emerged for these groups such as self-control, religious devotion, self-confidence and inwardness [14] self-determination, effective regulation of self and favorable self-perception [15] can be examined by their interaction with hope in resilience.

As well as the contributions indicated through this study, there are also some limitations that other researchers are advised to be critical with when referring to the overall framework and results emerged. One of these limitations of the study is the reliance on the self-report measures when collecting the data. In spite of the tentative assumption that participants provided genuine information, the accuracy of the information in such self-report measures form a limitation over the data. Another limitation of the study is pertinent to the participant selection method. The data for the study was collected from high school students living in socioeconomically disadvantaged districts. Despite the correspondence of participant characteristics to the aim of the study, randomization for selecting the sample may create different results other than this study.

\section{CONCLUSION}

The aim of this study was to test the role of hope in predicting resilience in socio-economically disadvantaged adolescents. Regression analysis was used to see the correlation as well as the predictive effect of hope to resilience levels of participants. As proposed, the results of regression analysis showed that hope explains nearly half of the variance (48\%) in resilience scores of adolescents by partially supporting the research question presented under this study.

The study has certain implications for future studies and practitioners as well. Current study implemented the dominance role of hope for a group of disadvantaged adolescents. Future studies examining the relations of hope to resilience in such groups may also focus on setting complex models to explain how hope brings in such predictive effects on resilience through individual/familial and social factors. The significant relationship of hope to resilience emerged in the study may also inform school counselors especially working in similar districts as regarding the emerged role of hope that could be a possible facilitator of resiliency and psychological well-being for adolescents they are working with. In addition, school counselors and educators who adopt a strength and competence based focus may take the predictive role of hope into account when organizing resilience or coping programs and interventions in adolescents with similar characteristics.

IJERE Vol. 7, No. 4, December 2018 : 299 - 304 


\section{REFERENCES}

[1] Stronks, K., Mheen, H. Van de, Bos J. van den \& Mackenbach, J. P. "The interrelationship between income, health and employment status". International Journal of Epidemiology, 26(3): 592-600; 1997.

[2] Snyder, C. R., Harris, C., Anderson, J. R., Holleran, S. A., Irving, L. M., Sigmon, S. T., et al. "The will and the ways: Development and validation of an individual-differences measure of hope". Journal of Personality and Social Psychology, 60, 570-585; 1991.

[3] Masten, A. \& Garmezy, N."Risk, vulnerability, and protective factors in developmental psychopathology. In B. Lahey \& A. Kazdin A (Eds)", Advances in Clinical Child Psychology, Vol. 8. (pp. 1-52). Plenum Press; New York; 1985.

[4] Embury, P. S. \& Saklofske, H. D. "Resilience interventions for youth in diverse populations". Springer, New York; 2014.

[5] Garmezy, N."Resiliency and vulnerability to adverse developmental outcomes associated with poverty". American Behavioral Scientist, 34, 416-430; 1991.

[6] Akman, Y. \& Korkut, F. "Umut ölçeği üzerine bir çalışma”. Hacettepe Üniversitesi Eğitim Fakültesi Dergisi, 9, 193-202; 1993.

[7] Aydın-Sünbül, Z. "The relationship between mindfulness and resilience among adolescents: mediating role of selfcompassion and difficulties in emotion regulation" (Unpublished doctoral dissertation). Middle East Technical University, Department of Educational Sciences, Ankara, 2016.

[8] Wagnild, G. M. "The Resilience Scale user's guide for the US English version of the resilience scale and the 14item resilience scale (RS-14)". Worden, MT: The Resilience Center; 2010.

[9] Zolkoski, M. S. \& Bullock, M. L.”Resilience in children and youth: A review”. Children and Youth Services Review, 34, 2295-2303; 2012.

[10] Harley, M. D. "Perceptions of hope and hopelessness among low-income African American adolescents" (Doctoral dissertation). The Ohio State University, Ohio, USA; 2011.

[11] Chen, E., \& Miller, E. G. "Shift-and-persist" strategies: Why low socioeconomic status isn't always bad for health". Perspectives on Psychological Science, 7 (2), 135-158; 2012.

[12] Hage, G. "Against paranoid nationalism: Searching for hope in a shrinking society". Pluto Press; Australia. 2003.

[13] Coleman, J. \& Hagell, A. "Adolescence, risk and resilience: Against the odds". John Wiley and Sons, Ltd. 2007.

[14] Wagnild, G. M., \& Young, H. M. "Development and psychometric evaluation of the resilience scale". Journal of Nursing Measurement, 1, 165-178; 1993.

[15] Garmezy, N. "Reflections and commentary on risk, resilience, and development". In R. Haggerty, L. Sherrod, N. Garmezy, \& M. Rutters (Eds.), Stress, Risk, and resilience in children and adolescents: Processes, mechanisms, and interventions (pp. 1-18). Cambridge: Cambridge University Press; 1994.

[16] Masten, S. A. "Regulatory processes, risk and resilience in adolescent development". Annals of The New York Academy of Sciences, 1021, 310-319; 2004.

[17] Newacheck, P. W., Hung, Y. Y., Park, M. J., Brindis, C. D., \& Irwin, C. E. "Disparities in adolescent health and health care: Does socioeconomic status matter?". Health Services Research, 38, 1235-1252; 2003.

[18] Masten, S. A. "Ordinary magic: Resilience process in development". American Psychologist, 56(3), 227-238; 2001.

[19] Hudson, G. C. "Socioeconomic status and mental illness: Tests of the social causation and selection hypotheses". American Journal of Orthopsychiatry, 75 (1), 3-18; 2005.

[20] Schneiders, J., Drukker, M., Ende, D. V. J., Verhulst, F. C., Os, V. J. \& Nicolson, A. N. "Neighbourhood socioeconomic disadvantage and behavioural problems from late childhood into early adolescence", J Epidemiol Community Health, 57, 699-703; 2003.

[21] Piotrowska, J. P., Stride, B. C., Croft, E. S. \& Rowe, R. "Socioeconomic status and antisocial behaviour among children and adolescents: A systematic review and meta-analysis". Clinical Psychology Review, 35, 47-55; 2015.

[22] Newacheck, P. W., Hung, Y. Y., Park, M. J., Brindis, C. D., \& Irwin, C. E. "Disparities in adolescent health and health care: Does socioeconomic status matter?”. Health Services Research, 38, 1235-1252; 2003.

[23] Stepleman, M. L., Wright, E. D. \& Bottonari, A. K. "Socioeconomic status: Risks and resilience. In S. L. \& M. S. (Eds.)", Determinants of minority mental health and wellness (pp. 273-302). New York: Springer; 2009.

[24] Mcclintock, B. J. "Hope among resilient African American adolescents" (Doctoral dissertation). Marquette University, Wisconsin, USA. 2009.

[25] Seligman, M. "Learned optimism: How to change your mind and your life". New York: Random House Inch. 1998.

[26] Snyder, C. R. "Hope theory: Rainbows in the mind". Psychological Inquiry, 13, 249-275; 2002.

[27] Miech, R. A., Caspi, A., Moffitt, T. E., Wright, B. R. E. \& Silva, A. P. "Low socioeconomic status and mental disorders: A longitudinal study of selection and causation during young adulthood". American Journal of Sociology, 104 (4), 1096-1131; 1999. 


\section{BIOGRAPHIES OF AUTHORS}

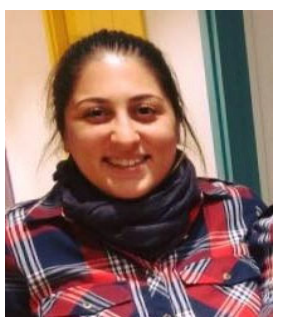

Dr. Zeynep Aydin Sunbul is an Assistant Professor of Psychological Counseling and Guidance at the Istanbul Medipol University, in Istanbul, Turkey. Her research interests are in positive psychology, mindfulness approaches, and adolescent development. She published studies on pro-social development of adolescents, child/adolescent mindfulness and resilience.

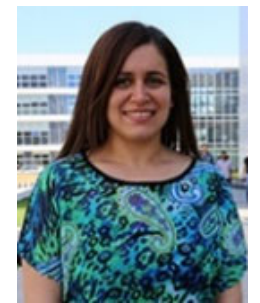

Dr. Ferah Çekici is an Assistant Professor of Psychological Counseling and Guidance at the Istanbul Medipol University, in Istanbul, Turkey. Her research interests are in cognitive-behavior therapy, positive psychology, and child/adolescent development. She published studies on positive psychology, individual and group counseling. 